\title{
Sentimento docente sobre a prática pedagógica: reflexões e avaliações
}

\section{Everton Bedin}

bedin.everton@gmail.com

0000-0002-5636-0908

Universidade Luterana do Brasil,

Canoas, Rio Grande do Sul, Brasil.

Universidade Federal do Rio

Grande do Sul, Porto Alegre, Rio

Grande do Sul, Brasil.

\section{José Claudio Del Pino}

delpinojc@yahoo.com.br

0000-0002-8321-9774

Universidade do Vale do Taquari,

Lajeado, Rio Grande do Sul, Brasil.

Universidade Federal do Rio

Grande do Sul, Porto Alegre, Rio

Grande do Sul, Brasil.

\section{RESUMO}

O texto divulga resultados de uma atividade desenvolvida para qualificar a formação inicial de professores de química, objetivando apresentar os impactos das Rodas de Conversa virtuais na formação inicial destes professores, possibilitando a emersão do sentimento docente sobre a própria prática pedagógica. Os dados coletados virtualmente nas Rodas de Conversa foram analisados de forma quali-quantitativa via Análise de Conteúdos e Teoria de Grafo. Os resultados são suficientes para romper com a resistência dentro dos cursos de formação de professores quando se cogita a possibilidade de desenvolver ações de extensão que favoreçam a sistematização das competências e habilidades dos futuros professores para criar, aperfeiçoar e aplicar metodologias de ensino.

PALAVRAS-CHAVE: Formação docente. Situação de estudo. Rodas de conversa. 


\section{INTRODUÇÃO}

Segundo a professora Bernardete Gatti (2014), diretora do Departamento de Pesquisas Educacionais da Fundação Carlos Chagas, um dos grandes problemas que envolvem a formação de professores no Brasil é a necessidade de incluir nas redes de ensino, já que o país apresenta uma escolarização tardia, "crianças e jovens de segmentos sociais que até poucas décadas atrás não eram atendidas pela educação básica" (p. 35). Assim, devido a necessidade de maximizar as redes de ensino e o curto espaço de tempo para formar profissionais da educação com competências e habilidades, houve, de acordo com estudos e avaliações disponíveis, a formação de profissionais com baixa qualificação, considerando como valores os "aspectos didático-pedagógicos necessários ao desempenho do trabalho docente" (ibidem).

Neste sentido, entende-se que o professor em formação inicial precisa ter um espaço adequado à suas especificidades e singularidades de formação, pois o pleno desenvolvimento da capacidade humana e seus significados se encontram nos processos educativos dos quais este faz parte; logo, a formação inicial "deve estimular uma perspectiva crítico-reflexiva, que forneça aos professores os meios de um pensamento autônomo e que facilite as dinâmicas de auto formação participada" (NÓVOA, 1997, p. 25). Afinal, na formação ativa do aluno da educação básica, o professor, enquanto personagem central e importante na disseminação e conexão do saber científico aos elementos substanciais do contexto do aluno, apresenta papel fundamental para enriquecer e mediar os processos de ensino e aprendizagem que qualificam a formação do aluno.

Assim, percebe-se a necessidade urgente de realizar ações referentes e sobre a formação inicial de professores com vistas, além de capacitá-los de forma consistente aos níveis de ensino, a propiciá-los infraestrutura e carreiras atrativas. Essas ações são necessárias no Brasil porque, de acordo com Gatti (2014, p. 36), não há, até o momento, "uma iniciativa nacional forte o suficiente para adequar o currículo às demandas do ensino, iniciativa que levasse a rever a estrutura dessa formação nas licenciaturas e a sua dinâmica".

Diante dos fatos, e considerando a formação inicial de professores como artefato único e ímpar na qualificação do ensino da educação básica à luz da formação crítico-reflexiva, constata-se que é necessária a revisão curricular e institucional do processo de formação inicial de professores. Todavia, sabe-se que os problemas a serem enfrentados nos campos institucional e curricular são inúmeros, dentre eles destacam-se, no campo institucional, a segmentação da formação dos professores, a descontinuidade na formação dos alunos da educação básica e o distanciamento entre as instituições de Ensino Superior e Ensino Básico. No campo curricular, destacam-se a desconsideração do conhecimento pessoal dos professores em formação, o tratamento inadequado dos conteúdos e sua ausência relativa às tecnologias, à pesquisa e à prática e a desconsideração das especificidades próprias dos níveis de ensino em que são atendidos os alunos da educação básica, assim como das etapas da educação básica e das áreas do conhecimento que compõem o quadro curricular desta educação (BRASIL, 2002).

Neste desenho, e considerando que o desenvolvimento de competências que compreendem as dimensões da atuação profissional do professor, do comprometimento aos valores estéticos, políticos e éticos inspiradores da sociedade democrática, o presente artigo tem por objetivo apresentar, por meio 
de um curso de formação, os impactos das Rodas de Conversa na formação inicial de professores e, em especial, uma avaliação docente sobre a própria prática pedagógica, considerando a metodologia de Situação de Estudo (SE) como artefato desta ação na educação básica, a qual, segundo a LDBEN, é a referência principal para a formação dos profissionais da educação.

O trabalho se justifica na medida em que apresenta resultados de um curso de formação por meio de Rodas de Conversa com o intuito de desenvolver metodologias de ensino para a educação básica na contemporaneidade e qualificar a formação docente inicial, afinal o objeto da formação docente é "possibilitar aos professores adquirir ou aperfeiçoar seus conhecimentos, habilidades, disposições para exercer sua atividade docente, de modo a melhorar a qualidade da educação que seus alunos recebem" (GARCIA, 1999, p. 26).

Nesta perspectiva, as Rodas de Conversa possibilitam aos professores em formação inicial, além da troca de saberes e a aprendizagem sobre metodologias educacionais, o contato com a escola antes das disciplinas de Estágios Curriculares, proporcionando-lhes entender sobre o papel social e cultural desta, desenvolver habilidades didáticas e competências sobre os conteúdos, aperfeiçoar a prática pedagógica e despertar a curiosidade pelo processo de investigação, referente a reflexão do/no próprio desenvolvimento profissional.

\section{O PROJETO RODAS DE CONVERSA COMO QUALIFICAÇÃO À FORMAÇÃO DOCENTE}

Acredita-se que a qualificação da aprendizagem escolar na educação básica, em especial no ensino de ciências/química, ocorra por meio do aperfeiçoamento das práticas pedagógicas e dos saberes docentes durante a formação inicial de professores, pois estes serão os agentes transformadores do cenário educacional atual. Neste desenho, buscando o supracitado, um dos projetos filantrópicos desenvolvidos em forma de curso de formação em uma universidade privada da região metropolitana da grande Porto Alegre, no Estado do Rio Grande do Sul, intitula-se "Rodas de Conversas na Universidade - Formação Docente Tecnológica em Ciências: metodologias de Projetos de Aprendizagem, Sequência Didática e Situação de Estudo de cunho interdisciplinar".

Neste projeto integram-se dez licenciandos do curso de química (PFI), um professor titular e uma professora de uma escola municipal da região, com o objetivo de, para além de pensar, construir e reconstruir metodologias de ensino que aproximam a realidade dos estudantes aos saberes científicos, refletir sobre as concepções específicas dos sujeitos sobre o ensino-aprendizagem, apontando para a necessidade do aperfeiçoamento e da qualificação na formação inicial, numa perspectiva de considerá-las expressamente necessárias as exigências contemporâneas, as quais decretam saberes, habilidades e competências específicas para diferentes contextos e situações.

Este projeto que se desenvolve em meio as Rodas de Conversa, estabelecidas como "estratégias política-libertadoras, que favorecem a emancipação humana, política e social de coletivos historicamente excluídos" (BEDIN; DEL PINO, 2016a, p. 1414), proporciona conversas formativas-dialógicas que possibilitam a produção e a ressignificação de saberes sobre as experiências dos professores em formação, tanto inicial quanto continuada, sobre metodologias de ensino. Assim, entende-se 
que "os sujeitos que as compõem se implicam, dialeticamente, como atores históricos e sociais críticos e reflexivos diante da realidade; a fala é compreendida como expressão de modos de vida" (BEDIN; DEL PINO, 2016a, p. 1415).

Basicamente, o projeto vem sendo desenvolvido com o intuito de propiciar aos sujeitos novas formas de ensinar e aprender, perceber a necessidade da formação permanente, possibilitar aos licenciandos a interação com a realidade da escola, oportunizar a professora da escola municipal a formação continuada em Rodas de Conversa e promover a relação entre a escola e a universidade, uma vez que, para a aplicação das metodologias desenvolvidas pelos PFI, há a necessidade de uma escola real, a qual apresente um grupo heterogêneo de estudantes com o objetivo de participar, socializar, ensinar e aprender.

Assim, percebe-se que estes momentos, oferecidos nas Rodas de Conversa, possibilitam aos professores em formação construírem a própria identidade docente seja por meio de reflexões individuais ou por meio da relação com o outro, pois integram momentos de influência mútua, diálogo e construção de significados sobre as questões que permeiam a formação docente. Logo, estes espaços têm proporcionado aos professores em formação inicial, em meio ao respeito recíproco e trocas de experiências e saberes, um processo de expressão de conceitos e opiniões sobre metodologias de ensino.

Estes espaços de formação docente se relacionam com as palavras de Bedin (2012, p. 52), pois para o autor estes são "espaços de debates, íntegras experiências e, entre outros, de relações humanas, que se tece e se enfatiza - por meio destas intensas mediações - a construção da identidade profissional, social e coletiva da profissão professor". Além do mais, as Rodas de Conversa "contribuem para a formação dos professores de forma significativa, uma vez que lhes possibilitam atualizar saberes, completar as práticas didáticas e ressignificar concepções em relação a formação para o ensino de ciências" (BEDIN; DEL PINO, 2017, p. 166).

Os mesmos autores, ainda ajuízam que nestes espaços de aperfeiçoamento da formação docente ocorrem "estudos, discussões, pesquisa e articulação de saberes entre os sujeitos sobre a ação de ensinar e aprender", onde se "constituem professores mais autônomos, ricos em conhecimento qualificado e, principalmente, aptos a desenvolverem, em meio a múltiplas competências e habilidades construídas e aperfeiçoadas no decorrer do processo e na relação com o outro" (BEDIN; DEL PINO, 2017, p. 167).

Assim, compreende-se que por meio das Rodas de Conversa existe uma horizontalização das relações de poder; os professores que as compõem se implicam, dialeticamente, como atores históricos-sociais e críticos-reflexivos diante da realidade do contexto social, uma vez que, para a qualificação dos processos de ensino e aprendizagem da educação básica, é preciso que as metodologias sejam continuadamente aperfeiçoadas para problematizar e exercer, com rigor e habilidade, a prática pedagógica.

Salienta-se que este projeto se divide em encontros presenciais e virtuais, mas, em ambas as formas, fundamenta-se num processo formativo-dialógico de trocas de saberes, onde se permite a conexão do conhecimento acadêmico com o conhecimento da prática da sala de aula. Assim, por meio de reflexões individuais e coletivas, promove-se melhorias aos processos de ensinar e aprender, uma vez que se estabelecem relações entre os saberes da formação inicial e os saberes da 
formação continuada para significar os conceitos científicos contextualizados e necessários à promoção da autonomia dos sujeitos da educação básica e permitir que possam desvelar a realidade em que estão inseridos.

Este projeto é importante na medida em que se entende que a formação de professores se encaminha na perspectiva apontada por Zanon e Schnetzler (2001). Estes autores enfatizam a importância da composição de tríades de interação profissional (professor universitário, em formação inicial e em formação continuada - professor da educação básica) para articular os diferentes saberes e minimizar a dicotomia estabelecida entre as formações inicial e continuada, a teoria e a prática e os processos de ensino e aprendizagem; logo, entende-se que as Rodas de Conversa "representam uma aposta significativa em que o ato educativo contextualizado demarca a imersão de sujeitos de direitos engajados no ato de conhecer e transformar a realidade" (BEDIN; DEL PINO, 2016a, p. 1415).

\section{A PESQUISA}

A pesquisa que aqui se apresenta é resultado de uma crítica realizada pelos PFI durante a prática pedagógica na escola parceira do projeto Rodas de Conversa. Em especial, analisou-se o sentimento docente que emerge na reflexão sobre a prática pedagógica durante a aplicabilidade da Situação de Estudo (SE) na escola municipal, o qual se estabeleceu por meio de um diálogo desenvolvido na parte virtual das Rodas de Conversa; um grupo fechado no Facebook com a presença do professor formador (PF) e dos professores em formação inicial (PFI).

$A E^{1}$ foi a metodologia trabalhada durante três meses nas Rodas de Conversa com os PFI. Posteriormente, em duplas, estes PFI deveriam esquematizar uma SE para ser desenvolvida no ensino de Ciências na escola. A importância da utilização da SE se releva quando Maldaner (2005, p. 10) ajuíza que "o indício da aprendizagem estará, justamente, na capacidade de reconstrução da situação sob estudo na forma conceitual, passando a constituir a mente dos aprendentes com novas formas de raciocínio, de abstração e de representação de mundo".

Como percepção para a discussão de forma virtual utilizou-se o grupo fechado no Facebook, pois se avalia que esse tem se constituído em espaços de trocas de saberes, experiências e conhecimentos tanto pedagógicos quanto específicos da formação de cada participante, pois nele se apresentam os sentimentos sobre a prática docente em formação inicial; momento em que o eu professor rega-se e constitui-se com o eu aluno. O grupo no Facebook é o espaço em que os PFI encontram para socializar suas certezas e questionar suas incertezas, tanto sobre as questões que regem as metodologias do professor quanto a constituição da própria identidade; é o período em que estes conseguem compartilhar os saberes, dialogar sobre as dificuldades e perceber que se encontram no desenvolvimento do ofício da prática.

Neste sentido, acredita-se que os momentos de Rodas de Conversa de forma virtual têm proporcionado aos professores a capacidade de desenvolver habilidades críticas e problematizadoras, enfatizando os aspectos metodológicos e conceituais da prática docente, e, singularmente, estabelecido reflexões e articulações entre conhecimento científico e outros de natureza social e epistemológica. Estas interfaces, por se constituírem enquanto mecanismos de emersão para o diálogo e o entretenimento entre os PFI e a rede, "devem oferecer 
aos estudantes e aos professores variadas opções de navegação e facilidades na localização e troca das informações, favorecendo o processo de construção de saberes por meio da interação e da colaboração" (BEDIN; DEL PINO, 2016b, p. 17).

Assim, justifica-se a ideia de assumir o Facebook como rede social capaz de oferecer a continuidade do curso de formação de forma virtual, pois nele foi possível a criação de um espaço de interação entre o PF e os PFI (CALDEIRA; DA SILVA; MAGDALENA, 2015), tendo em vista as estratégias cognitivas criadas para a escrita de novas postagens numa perspectiva coletiva de criação (FRAGA et al., 2011), além de ser motivador e significativo para disseminação de materiais didáticos e estratégias para ensinar/aprender.

Ainda, de acordo com Bedin e Del Pino (2016b, p. 8), o Facebook é importante porque "proporciona interações sociais simultaneamente, não apenas de maneira síncrona em um chat, mas de maneira assíncrona em um grupo fechado, emergindo um diálogo com criticidade e autonomia de forma colaborativa". Corroborando, Ferreira, Campos, Bártholo e Markenson (2014, p. 17) justificam a escolha da rede por se propagar como "uma instância de apoio administrativo ao trabalho docente em função da configuração deste espaço e de suas possiblidades como um ambiente informal de partilha". Assim, o Facebook é uma "plataforma de qualificação aos processos de ensino e aprendizagem, pois oferece potencial para a aprendizagem coletiva que perpassa debates que envolvem questões contemporâneas de ensino-aprendizagem" (BEDIN; DEL PINO, 2016b, p. 17).

Portanto, tem-se que a pesquisa se classifica como qualitativa no viés de um estudo de caso de cunho etnográfico, buscando elucidar a realidade completa e o aperfeiçoamento da formação pedagógica dos envolvidos por meio de múltiplas fontes de informação (LÜDKE; ANDRÉ, 2013). Do mesmo modo, parte de uma pesquisa com a perspectiva netnográfica, também conhecida como etnografia virtual, pois é uma metodologia científica utilizada para observar comunidades presentes na Internet, quanto à influência na vida de seus membros (HINE, 2005, p. 47). Além do mais, segundo Kozinets (2010), não é mais possível estudar uma determinada cultura/vida social sem integrar o estudo da Internet e da comunicação mediada por computadores.

\section{RESULTADOS E DISCUSSÕES}

\section{A coleta de dados}

Destaca-se que as colocações dos PFI, que ocorreram nas Rodas de Conversa em meio virtual, deram-se por meio de uma questão disponibilizada pelo PF. Esta forma de abordar a questão foi importante por possibilitar, no intercâmbio de ideias e percepções sobre a realidade da prática pedagógica, um diálogo diário de aprendizagem e formação entre os PFI e o PF. Assim, entende-se que as interações ocorreram de forma a garantir o crescimento pessoal e profissional dos sujeitos, pois estes asseguraram a relação e o crescimento por meio de críticas, sugestões e argumentos reflexivos e ricos relacionados a própria prática pedagógica.

Para haver diálogo no Facebook é preciso, dentre outros, colaboração e afetividade dos integrantes, o que necessita de conhecimento e saber para opinar e socializar suas concepções. Assim, conforme Bedin e Del Pino (2016b, p. 9), 
buscou-se, no cerne do grupo, organizar um momento de discussão em que "o praticante se sentisse à vontade, entendendo que é um espaço de criação e recriação de conhecimento, no qual ele poderia colaborar, argumentar, questionar". Ademais, a figura 1 abaixo apresenta a questão disponibilizada na rede para a constituição do diálogo nas Rodas de Conversa de forma virtual.

Figura 1 - Questão disponibilizada aos PFI no grupo do Facebook para emersão do diálogo de forma virtual.

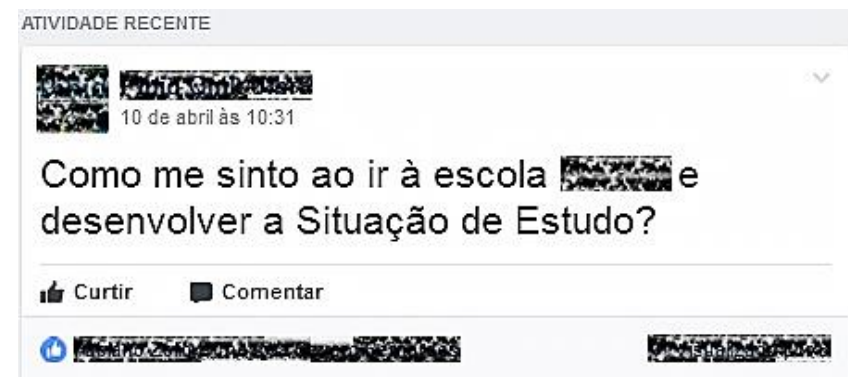

Fonte: Autores (2017).

Para analisar as colocações dos PFI, as quais se consideraram neste trabalho como sentimentos em relação a própria prática pedagógica que emergem a partir da reflexão, utilizou-se a Teoria de Grafo em uma vertente quantitativa e na vertente qualitativa utilizou-se a Análise de Conteúdos. Esta última análise consiste em um conjunto de técnicas de interpretação sobre as relações por meio de procedimentos sistemáticos e objetivos de exposição do conteúdo das escrituras, permitindo a inferência de conhecimentos relativos às condições de produção e recepção (BARDIN, 2006).

O conjunto de técnicas utilizado para interpretar as escrituras na rede, de acordo com Freitas, Cunha e Moscarola (1997, p. 15), "é uma técnica refinada, que exige muita atenção e cautela, paciência e tempo do pesquisador, o qual tem de se valer da intuição, imaginação e criatividade, principalmente na definição de categorias de análise". Esta parte é importante por apresentar as categorias que são rubricas ou classes que reúnem um grupo de elementos sob um título genérico, efetuado em razão dos caracteres comuns destes elementos (BARDIN, 2006).

Neste sentido, é necessário mencionar que a utilização da Teoria de Grafo se destaca em uma rede por apresentar subsídios significativos para que o pesquisador possa compreender a ligação entre os sujeitos e as categorias que emergem com a Análise de Conteúdos. Um grafo, segundo Rezende (2002), é uma representação de um conjunto de nós conectados por arestas que, em conjunto, formam uma rede. Basicamente, estes nós e arestas são os sujeitos em interação, os quais "possibilitam a construção de laços sociais que permitem ao sujeito buscar em seu semelhante um sentimento de pertencimento a determinado grupo e isso é possível através de ideais e objetivos comuns" (CANABARRO; BASSO, 2013, p. 3).

Além do mais, torna-se cogente ajuizar que a Teoria de Grafo foi realizada a partir do software Ucinet ${ }^{2}$, o qual é considerado um programa, compatível ao Windows, que cria matrizes à serem analisadas e interpretadas de forma virtual. Afinal, na análise da Teoria de Grafo a representação que se esboça a partir da interação dos atores nas redes sociais é realizada por meio de um grafo, o qual torna mais acessível e compreensível as informações advindas das interações. 
Em suma, este software tornou-se importante na análise de interações nas redes sociais por otimizar a mineração de dados a partir da rotina frenética das mesmas. Logo, o software apresenta múltiplas ferramentas para os afazeres de estatísticas e demonstrações integradas, as quais permitem a transformação de dados obtidos a partir das redes em visualizações gráficas de rápida consulta e leitura. Os indicadores que podem ser calculados com o uso do Ucinet são muitos, mas dentre os principais tem-se a densidade da rede e o grau de centralidade.

\section{Interpretando os dados e proliferando informações}

Antes de apresentar as reflexões sobre os resultados, é importante lembrar que a análise dos dados foi realizada pelo pesquisador responsável pelo trabalho, isto é, a análise parte do ponto de vista deste pesquisador e os dados qualificados abaixo se referem à parte participante da atividade do grupo. Sendo assim, qualquer análise referente a outro olhar pode, de alguma forma, surtir efeitos totalmente diferentes a estes, pois aqui, implicitamente, tem-se as reflexões do pesquisador que acompanhou de perto toda a atividade desenvolvida nas Rodas de Conversa.

Para análise quantitativa, como supracitado, optou-se em trabalhar com a Teoria de Grafos em um viés de análise sociométrica das relações estabelecidas no grupo, já que esta técnica representa graficamente uma rede. Ao observar o grafo abaixo (figura 2), pode-se perceber um conjunto de nós interconectados - aqui definidos como $\mathrm{PFI}$ - e as interconexões que representam suas relações; "os atores atuam de forma a moldar as estruturas sociais, através da interação e da constituição de laços sociais" (RECUERO, 2009, p. 26).

Figura 2 - Grafo elaborado pelo software UCINET por meio das interações entre os sujeitos nas Rodas de Conversa de forma virtual.

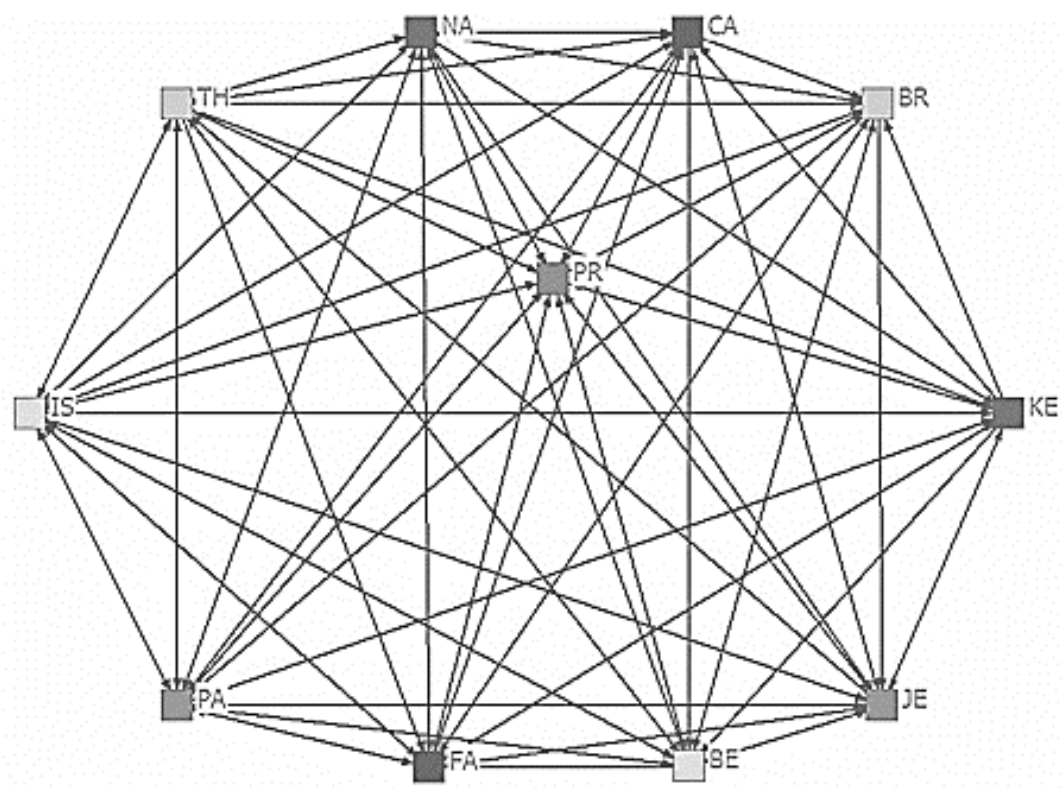

Fonte: Autores (2017).

No grafo é possível perceber as ligações entre os PFI, identificados pelas iniciais de seus nomes, e o Professor-formador, identificado como PF. As setas que 
saem de cada sujeito, indiferente de ser comentário, crítica ou sugestão ao colega, apresentam o sentimento individual em relação a prática pedagógica realizada na escola. Ademais, por meio das diferentes tonalidades, é possível perceber quem eram os PFI que contemplavam a dupla no trabalho desenvolvido. Por exemplo, o PFI FA apresenta uma tonalidade de cinza idêntica a tonalidade apresentada pela PFI CA, pois estes constituíram uma dupla de trabalho. Da mesma forma, os PFI BE e IS, PA e JE, KA e NA, TH e BR.

Ao observar o grafo, ainda, pode-se perceber que existe uma centralidade sujeito configurado como significativo na relação entre as pessoas; trata-se de sua posição superior em relação aos outros, considerando como medida a quantidade de elos que se estabelecem entre eles - sujeito que assume a centralidade pela abundância de laços de popularidade. Embora não se trate de uma posição fixa, hierarquicamente determinada, a centralidade em uma rede traz consigo a concepção de poder; logo, "quanto mais central é um indivíduo, mais bem posicionado ele está em relação às trocas e à comunicação, o que aumenta seu poder na rede" (BEDIN; DEL PINO, 2016b, p. 14).

Ao analisar as tabelas 1 e 2 abaixo, pode-se perceber que a centralidade da rede ficou estabelecida ao PF, pois este é o nó que atribui importância aos outros atores em função do fluxo de conexões que passam por ele para interligar os outros atores, de forma prática e rápida. Neste desenho, tem-se que a centralidade é a propriedade que auxilia a identificação de situações relevantes que verificam a importância de um sujeito em relação aos demais, sendo ordenado em função da importância que estabelece na rede por meio do número de ligações que constitui com os demais nós.

Tabelas 1 e 2 - Dados extraídos do software UCINET sobre a centralidade do grupo de discussão virtual das Rodas de Conversa

Actor Information Centralities
\begin{tabular}{|c|c|}
\hline & Inform \\
\hline $1 \mathrm{TH}$ & 11.113 \\
\hline $2 \mathrm{BR}$ & 9.924 \\
\hline $3 \mathrm{BE}$ & 9.610 \\
\hline $4 \mathrm{IS}$ & 8.853 \\
\hline $5 \mathrm{PA}$ & 9.611 \\
\hline $6 \mathrm{JE}$ & 11.324 \\
\hline $7 \mathrm{NA}$ & 10.547 \\
\hline $8 \mathrm{KE}$ & 10.198 \\
\hline $9 \mathrm{FA}$ & 10.541 \\
\hline $10 \mathrm{CA}$ & 10.236 \\
\hline $11 \mathrm{PR}$ & $\mathbf{1 2 . 3 8 8}$ \\
\hline
\end{tabular}

\begin{tabular}{|l|l|c|l|l|}
\hline & $\begin{array}{c}1 \\
\text { Outdeg }\end{array}$ & $\begin{array}{c}2 \\
\text { Indeg }\end{array}$ & $\begin{array}{c}3 \\
\text { Noutdeg }\end{array}$ & $\begin{array}{c}4 \\
\text { Nindeg }\end{array}$ \\
\hline 1 TH & 15.000 & 14.000 & 0.375 & 0.350 \\
\hline 2 BR & 12.000 & 12.000 & 0.300 & 0.300 \\
\hline 3 BE & 10.000 & 13.000 & 0.250 & 0.325 \\
\hline 4 IS & 13.000 & 10.000 & 0.325 & 0.250 \\
\hline 5 PA & 12.000 & 11.000 & 0.300 & 0.275 \\
\hline 6 JE & 12.000 & 16.000 & 0.300 & 0.400 \\
\hline 7 NA & 18.000 & 12.000 & 0.450 & 0.300 \\
\hline 8 KE & 11.000 & 12.000 & 0.275 & 0.300 \\
\hline 9 FA & 11.000 & 16.000 & 0.275 & 0.400 \\
\hline 10 CA & 13.000 & 12.000 & 0.325 & 0.300 \\
\hline 11 PR & $\mathbf{2 4 . 0 0 0}$ & $\mathbf{2 3 . 0 0 0}$ & $\mathbf{0 . 6 0 0}$ & $\mathbf{0 . 5 7 5}$ \\
\hline
\end{tabular}

Fonte: Autores (2017).

Ainda, sobre o grafo, é necessário que seja calculada a densidade; esta propriedade tem relação com a quantidade de conexões existentes. Granovetter (1992) explica que quanto maior for o número de conexões, mais informações são compartilhadas sobre o que os sujeitos estão fazendo e, portanto, se tem uma melhor habilidade para afeiçoar os comportamentos. A densidade de uma rede é medida pela extensão na qual está altamente interconectada (BRASS, BUTTERFIELD; SKAGGS, 1998) por meio de cálculos realizados com a fórmula da equação 1 . Assim, se considera que a densidade (D) de uma rede é definida como uma relação entre o número de arestas (E) para o número de arestas possíveis, dada pelo coeficiente binomial (N/2). 


$$
\begin{aligned}
& \mathrm{D}=\frac{2 \mathrm{E}}{\mathrm{N}(\mathrm{N}-1)} \\
& \text { Fonte: Autores (2015). }
\end{aligned}
$$

No software Ucinet existe uma parte específica que consegue, automaticamente, calcular a densidade do grafo. Para o grafo acima, a densidade se apresenta na tabela 3.

Tabela 3 - Dados extraídos do software UCINET sobre a densidade do grafo que representa a discussão virtual das Rodas de Conversa

\begin{tabular}{|c|c|c|c|c|l|l|}
\hline & $\begin{array}{c}1 \\
\text { Size }\end{array}$ & $\begin{array}{c}2 \\
\text { Avg Deg }\end{array}$ & $\begin{array}{c}3 \\
\text { Density }\end{array}$ \\
\hline $1 \mathrm{TH}$ & 10.000 & 12.200 & 1.356 \\
\hline $2 \mathrm{BR}$ & 10.000 & 12.700 & 1.411 \\
\hline $3 \mathrm{BE}$ & 10.000 & 12.800 & 1.422 \\
\hline $4 \mathrm{IS}$ & 10.000 & 12.800 & 1.422 \\
\hline $5 \mathrm{PA}$ & 10.000 & 12.800 & 1.422 \\
\hline 6
\end{tabular}

\begin{tabular}{|c|c|c|c|}
\hline $6 \mathrm{JE}$ & 10.000 & 12.300 & 1.367 \\
\hline $7 \mathrm{NA}$ & 10.000 & 12.100 & 1.344 \\
\hline 8 KE & 10.000 & 12.800 & 1.422 \\
\hline 9 FA & 10.000 & 12.400 & 1.378 \\
\hline $10 \mathrm{CA}$ & 10.000 & 12.600 & 1.400 \\
\hline $11 \mathrm{PR}$ & 10.000 & 10.400 & 1.156 \\
\hline
\end{tabular}

Fonte: Autores (2017)

Analisando-se as tabelas acima, pode-se observar que o grafo deveria apresentar uma densidade de relações superior àquela apresentada, pois ao calcular a densidade do mesmo chegou-se ao resultado de 1.373 relações. Contudo, o grafo apresenta uma média de 151 relações, isto porque a densidade do grafo é expressa por meio da relação entre o número de ligações potenciais e as verdadeiramente presentes neste; logo, é possível perceber no grafo acima que $\mathrm{KE}$ se relaciona com $\mathrm{BR}$, mas $\mathrm{BR}$ não se relaciona com $\mathrm{KE}$.

Esta ação de relacionamentos de um PFI para com o outro, sem receber um respaldo, ocorre várias vezes no gafo, diminuindo significativamente o número de relações. Todavia, é possível entender que a baixa densidade do grafo não interferiu, de forma alguma, no objetivo desenhado, afinal como o intuito deste trabalho foi avaliar os sentimentos docentes por meio do diálogo na rede, o ideal é usá-lo com uma baixa densidade para se tornar viável, a olho nu, avaliar a relação e a conexão entre os nós (SANTOS, 2013).

Assim, entende-se que, de acordo com Alves (2010, p. 159), “[...] a aprendizagem em rede enfatiza processos colaborativos na medida em que permite ao grupo vivenciar distintos papéis e momentos, nos quais a comunicação é descentralizada, permitindo que diferentes vozes sejam escutadas". Portanto, percebe-se que o desenho das Rodas de Conversa de forma virtual tem proporcionado aos sujeitos a exposição e amadurecimento de seus sentimentos em relação a própria prática pedagógica. Isto é possível porque as Rodas de Conversa desenvolvidas no viés do Facebook propiciaram o diálogo de forma significativa entre os sujeitos, constituindo-se dentro de um espaço favorável ao compartilhamento da informação e do conhecimento. 
Em relação as categorias que emergiram na Análise de Conteúdos por meio da interpretação das escrituras dos PFI, percebe-se que estas, dentro de um determinado percentual, revelam a importância de ir à escola e desenvolver as atividades planejadas no decorrer das Rodas de Conversa à luz da SE para um enriquecimento pessoal. Em outras palavras, ir à escola e desenvolver as atividades planejadas durante o curso de formação, para os professores em formação inicial, é o momento de desenvolver de forma eficaz o planejamento e comprovar os desafios existentes nas pressuposições teóricas da graduação; é um processo de confrontamento entre o eu aluno e o eu professor.

Nesta perspectiva, entende-se que a formação inicial de professores se constitui em uma importante fase para a construção da identidade destes profissionais, e, por esse motivo, "toda a prática e todas as experiências vivenciadas por eles influenciam diretamente no rumo posterior de suas ações e concepções acerca da instituição escolar e da relação ensino-aprendizagem" (ANJOS, et al., 2014, p. 130). Corroborando, Garcia $(2009$, p. 7) afirma que a identidade docente afeta no desenvolvimento dos ambientes de aprendizagem, pois "o compromisso pessoal, a disponibilidade para aprender a ensinar, as crenças, os valores, o conhecimento sobre as matérias que ensinam e como as ensinam, as experiências passadas, assim como a própria vulnerabilidade profissional" fazem parte da constituição do ser professor.

Assim, a formação que ocorre nas Rodas de Conversa virtuais intensifica a troca de sentimentos entre os professores e a reflexão sobre a própria prática, munindo-os de habilidade e competências para se constituírem enquanto professores inovadores. Afinal, a formação docente "contempla uma componente prática, integradora de todos os saberes, designada por prática pedagógica. Decisiva para uma formação de qualidade, visa proporcionar uma aproximação gradual do futuro professor à realidade da escola" (OLIVEIRA; VASCONCELOS, 2010, p. 127).

Como artefato de maximização e qualificação das categorias, abaixo, na tabela 4, apresenta-se uma parte do diálogo que ocorreu na rede como mecanismo de comunicação entre os sujeitos e, na sequência, um gráfico percentual que retrata as categorias que emergiram na Análise de Conteúdos sobre o diálogo.

Tabela 4 - Exposição explícita do debate virtual que ocorre nas Rodas de Conversa

TH: O desenvolvimento da Situação de Estudo na escola está sendo uma excelente oportunidade para adquirir experiência como professora, pois posso lecionar de uma forma independente e ao mesmo tempo ter o apoio dos colegas e do professor do projeto. Até o momento, lecionei em apenas uma aula para o 70 ano, mas toda a preparação e o envolvimento que as aulas da SE exigem estão me proporcionando uma boa base prática. $\mathrm{Na}$ primeira aula da aplicação da $\mathrm{SE}$, acreditei que estaria nervosa/ansiosa com o primeiro contato com alunos, mas me senti muito à vontade com a posição de professora, a aula transcorreu como o planejado e a certeza de ter escolhido a profissão certa se concretizou.
IS: Boa tarde pessoal! Reativei meu Facebook para poder participar aqui do grupo e trocarmos nossas experiências. Em resposta à pergunta, me sinto privilegiada ao ir à escola e desenvolver a SE. Digo isso porque acredito que é uma oportunidade incrível de desenvolvimento profissional (como futura professora), mas também pessoal, já que aprendemos muito com os alunos. Indo à escola, torna-se possível adquirir experiência, aprender sobre o papel do docente na formação dos alunos, além de compartilhar conhecimento e gerar valor - para os dois lados. Desenvolver uma SE exige dedicação, trabalho e o estudo propriamente dito. Sou relativamente nova no grupo e estou gostando dessa metodologia, pois assim me sinto mais preparada à ministrar aula. A SE proporciona uma certa lógica/sequência entre às atividades 
oportunidade de aplicar o conhecimento teórico através de projetos desenvolvidos com base nas SE, proporciona à nós uma formação mais completa e eficiente.

PR: TH, e quanto a desenvolver uma metodologia que você não conhecia, você a conhecia antes de iniciar o projeto? Será que a SE é importante para os alunos? Eu me faço seguidamente estes questionários... porque sei que temos que pensar em algo criativo e que desperte nos alunos a vontade em aprender, ainda somando a aprendizagem de vocês que estão em formação inicial.

TH: Antes de ingressar no projeto não conhecia a metodologia de SE. Para mim, percebi que empregar um método para desenvolver aulas é muito norteador. Para os alunos, a aplicação de aulas diferenciadas, fugindo da prática tradicional, é fundamental para tirá-los da inércia de apenas absorver o conteúdo. que vão sendo trabalhadas em sala, de forma que uma aula vai dando continuidade à outra, relacionando-as com o cotidiano dos alunos e, dessa forma, procurando maximizar o processo de ensino e aprendizagem. Em relação ao semestre passado, por exemplo, particularmente sinto que trabalhar com SE tornou o planejamento das aulas mais organizado. Nesse sentido, a SE auxiliou bastante, de forma que na primeira ida à escola já sabíamos o que seria trabalhado na última aula do trimestre. Claro que ela permite aperfeiçoamento e alterações das atividades a serem realizadas, mas acredito que em relação ao semestre passado, no atual sinto que a SE contribuiu bastante para o planejamento. De certa forma, isso também faz com que eu me sinta mais preparada e segura ao ir realizar uma atividade com os alunos.

Fonte: Acervo da pesquisa (2017).

Das colocações acima apresentadas pelos PFI diante do diálogo nas Rodas de Conversa de forma virtual foi possível, por meio da Análise de Conteúdo, plotar o gráfico abaixo que apresenta, como supracitado, as categorias que emergiram. Há de se destacar que esta emersão adveio das fases significativas do processo de qualificação por meio da Análise de Conteúdos, a qual se organiza em torno de três polos: "1. pré-análise; 2. exploração do material; e, por fim, 3. tratamento dos resultados: a inferência e a interpretação” (BARDIN, 2006, p. 121).

Figura 3-Gráfico representacional sobre as categorias e suas respectivas percentagens que, por meio da Análise de Conteúdos, emergem em meio ao diálogo virtual das Rodas de Conversa.

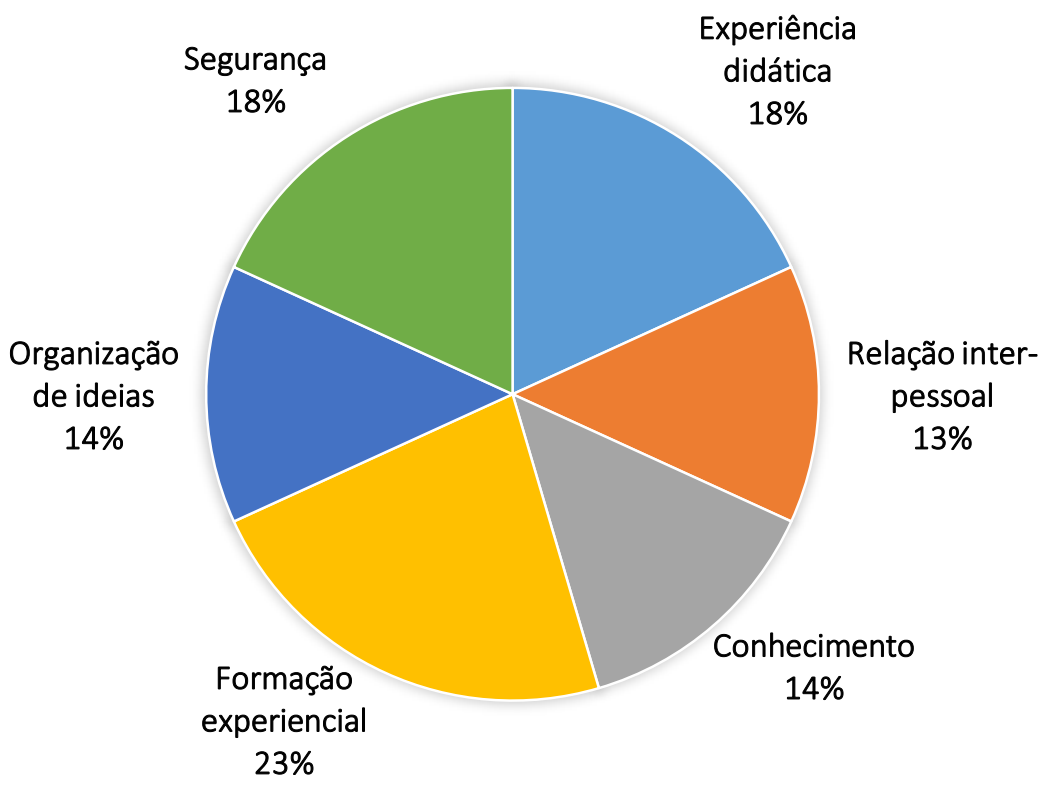

Fonte: Autores (2017). 
prática pedagógica na escola municipal trazem a concepção de que a prática abraça, como princípio norteador, a formação experiencial, o que não é possibilitado para aqueles licenciandos que não fazem parte das Rodas de Conversa. Esta categoria emerge com força nas colocações de Tardif (2007), quando este expõe que os saberes da experiência advêm da história de vida pessoal de cada professor; são produzidos por estes no cotidiano de sua prática; "[...] não provém das instituições de formação nem dos currículos. [...] não se encontram sistematizados em doutrinas ou teorias" (p. 48).

Como categorias secundarias tem-se a Experiência didática e a Segurança; logo, o diálogo na rede auxiliou os professores a entenderem o papel de ensinar e aprender em relação ao outro, pois na troca de informações os PFI trocavam experiências didáticas e, a partir do outro, forjavam segurança/confiança na/pela própria prática. Estas colocações encontram base nos saberes da didática, apresentados por Pimenta e Anastasiou (2002, p. 71) como aqueles "responsáveis pela articulação da teoria da educação e da teoria de ensino para ensinar nas situações contextualizadas", e na base pedagógico-didática, apresentada por Braslavsky (1999), a qual se refere à competência de conhecer, filtrar, usufruir, avaliar, aperfeiçoar e recriar táticas de intervenções didáticas.

Por fim, as três últimas categorias que emergem a partir das colocações dos professores, como se fossem um fio condutor à maximização de atividades para inferir ações na própria prática, encontram-se a Organização de ideias, o Conhecimento e a Relação interpessoal. Assim, torna-se fundamental perceber que as colocações dos PFI, mesmo diante de um espaço informal, se conectam de forma a conceber uma relação na formação inicial, pois configuram a experiência como artefato de adquirir segurança e didática para intervir na realidade do aluno, organizar suas ideias e constituir saberes na interrelação entre os sujeitos. Nesta direção, Tardif (2007) assinala uma nova perspectiva de professor para a contemporaneidade:

\footnotetext{
Um professor de profissão não é somente alguém que aplica conhecimentos produzidos por outros, não é somente um agente determinado por mecanismos sociais: é um ator no sentido forte do termo, isto é, um sujeito que assume sua prática a partir dos significados que ele mesmo lhe dá, um sujeito que possui conhecimentos e um saber-fazer provenientes de sua própria atividade e a partir dos quais ele a estrutura e a orienta (TARDIF, 2007, p. 230).
}

Esta ação mensura a concepção de que as Rodas de Conversa de forma virtual, além de proporcionarem aos futuros professores momentos de reflexões sobre o processo da própria formação, entendendo as características e especificidades do ensino de ciências em um percurso histórico marcado pelas certezas e incertezas da prática docente, à luz da reestruturação curricular via a metodologia SE como proposta de trabalho, intensifica a prática pedagógica realista, a fim de que estes possam se constituir em professores mais autônomos, ricos em conhecimento qualificado e aptos a desenvolverem um ensino de ciências em que o aluno é o ponto chave da formação sócio científica (BEDIN; DEL PINO, 2017).

Por fim, acredita-se que o principal ponto das Rodas de Conversa é auxiliar os futuros professores à: 
contexto determinado, do planejamento, do diagnóstico e da avaliação; proporcionar as competências para ser capazes de modificar as tarefas educativas continuamente [...] (IMBERNÓN, 2006, p 69).

\section{CONSIDERAÇÕES FINAIS}

Adentrar na realidade da escola pública para, em meio a socialização de atividades e práticas pedagógicas arquitetadas, qualificar a formação docente inicial e continuada, assim como os processos de ensino e aprendizagem, é uma forma de encarrar a realidade atual e a resistir. Assim, pode-se entender que estranhar uma situação tida como natural é o início da ação de compreender que aquela realidade só se moldará após a descoberta das possibilidades de modificar a situação que lhe deu origem.

Assim, relembra-se que esta pesquisa, como pano de fundo, possibilitou entender como as Rodas de Conversa podem impulsionar a formação docente, seja de forma virtual ou presencial, especialmente quanto a reflexão avaliativa sobre a própria prática pedagógica durante a formação inicial, considerando a metodologia de SE como artefato da ação pedagógica na educação básica. Nesta perspectiva, foi possível perceber, por meio da tabela 4 e do Grafo estabelecido entre as provocações erigidas nas Rodas de Conversa, que múltiplas reflexões e sentimentos sobre a própria prática no contexto escolar nasciam na medida em que os sujeitos interagiam, expressando suas inquietações e expectativas.

Diante dos fatos, entende-se ser necessário, nas diferentes universidades do país, o desenvolvimento de cursos que abracem as ideias propostas no curso de formação exposto neste artigo como Rodas de Conversa, pois, por meio dele e da relação estabelecida com uma escola municipal, foi possível proporcionar aos PFI a ação da reflexão no/durante o ato pedagógico, autonomia, competências e habilidades para promoverem um diálogo rico de informações e saberes na rede em meio a troca de ideias e experiências à luz da qualificação dos processos de ensinagem.

Ainda, é necessário afirmar que a aplicabilidade da prática docente na escola ocorreu por meio da metodologia de SE, a qual favoreceu a emersão das referidas categorias à luz dos sentimentos docentes, uma vez que tal proposta metodológica é empregada para modificar a maneira em que o professor e o aluno atuam na escola, pois faz com que este último possa investigar, refletir e resolver um problema. Da mesma forma, trabalhar com SE fez com que os PFI pudessem planejar em conjunto e romper com a forma tradicional de apresentar os conteúdos, normalmente estabelecida pelo sistema.

Por fim, tem-se que o desenho apresentado e refletido neste artigo é suficiente para romper com a resistência existente dentro dos cursos de formação de professores quando se cogita a possibilidade de desenvolver cursos durante a graduação que favoreçam a sistematização das competências e habilidades dos futuros professores, dentro de suas especificidades e particularidades, para criar, aperfeiçoar e aplicar metodologias de ensino-aprendizagem que qualificam o repertório docente, a aprendizagem discente e os processos de ensinagem na rede pública. Portanto, entende-se que os impactos das Rodas de Conversa na formação dos futuros professores acabam por refletir no berço da escola, participante do projeto, pois é em meio a estas que os PFI aprendem, aperfeiçoam, socializam e 
produzem conhecimentos de maneiras cooperativa, colaborativa e construtiva, transpassando os muros da universidade para à escola. 


\title{
Teacher feeling about pedagogical practice: reflections and evaluations
}

\begin{abstract}
The text divulges results of an activity developed to qualify the initial formation of professors of chemistry objectifying the impacts of the virtual Circles of Conversations in the initial formation of these teachers, making possible the emersion of teacher feeling about the pedagogical practice itself. The data collected virtually on the Circles of Conversations were qualitatively and quantitatively analyzed through Content Analysis and Graph Theory. The results are sufficient to break with the resistance within teacher training courses when it is a possibility of the to develop extension actions that favor a systematization of the skills and abilities of future teachers to create, improve and apply teaching methodologies.
\end{abstract}

KEYWORDS: Teacher formation. Study situation. Circles of conversations. 
1. A Situação de Estudo foi uma metodologia elaborada, analisada e aplicada pelo Grupo Interdepartamental de Pesquisa sobre Educação, da Universidade Regional do Noroeste do Estado do Rio Grande do Sul (GIPEC/UNIJUÍ), sendo referência no país, deste 0 ano de 2000. Link para conhece-la: http://www.projetos.unijui.edu.br/gipec/modules/conteudo/?tac=2

2. UCINET é um dos aplicativos mais abrangentes para a análise de redes sociais e aproximação de dados. Este software contém muitas rotinas analíticas para analisar uma rede. Link para download: https://sites.google.com/site/ucinetsoftware/downloads. Outras informações podem ser acessadas em: http://www.software.com.br/p/ucinet.

\section{REFERÊNCIAS}

ALVES, Lynn. Aprendizagem em rede e formação docente: trilhando caminhos para a autonomia, a colaboração e a cooperação. In: VEIGA, Ilma; D'ÁVILA, Cristina. (Org.). Profissão docente: novos sentidos, novas perspectivas. 2. ed. Campinas, SP: Papirus 2010.

ANJOS, Tiago Ribeiro dos; PEREIRA, Lais Rodrigues; ORLANDINI, Priscila; OZELO, Helka Fabbri Broggian. Contribuições do PIBID na formação de professores: uma reflexão continuada. Polyphonía, v. 25/1, jan./ jun. 2014.

BARDIN, Laurence. Análise de conteúdo. Lisboa: Edições 70, 2006.

BEDIN, Everton. Formação de professores de química: um olhar sobre o Pibid da Universidade Federal de Uberlândia. p. 166. Dissertação (Mestrado em Educação em Química) - Programa de Pós-Graduação em Química, Universidade Federal de Uberlândia, Uberlândia, 2012.

BEDIN, Everton; DEL PINO, José Claudio. Rodas de Conversa na Universidade Formação Docente Tecnológica em Ciências: metodologias de cunho interdisciplinar. Revista de la Facultad de Ciencia y Tecnologia, v. 1, p. 14131419, 2016a.

BEDIN, Everton; DEL PINO, José Claudio. A importância das redes sociais no ensino médio politécnico: aprendizagem colaborativa. \#Tear: Rer. de Educação Ciência e Tecnologia, v.5, n.1, 2016b.

BEDIN, Everton; DEL PINO, José Claudio. Concepções de professores sobre situação de estudo: rodas de conversa como práticas formadoras. Interfaces da Educ., Paranaíba, v.8, n.22, p.154-185, 2017. 
BRASLAVSKY, Cecília. Bases, orientaciones y criterios para el diseño de programas de formación de profesores. Revista Iberoamericana de Educación, n. 19, p. 1-28 1999.

BRASS, Daniel; BUTTERFIELD, Kenneth; SKAGGS, Bruce. Relationships and unethical behavior: a social network perspective. Academy of Management Review, v. 23, p. 14-31, 1998.

BRASIL. Resolução CNE/CP 01. Brasília, DF: Diário Oficial da União, 2002.

CALDEIRA, Maria Lúcia; DA SILVA, Mônica Ferreira; MAGDALENA, Michele. Blogs na área de educação: inovação, conhecimento e aprendizagem. Nuevas Ideas en Informática Educativa TISE. Rio de Janeiro, 2015.

CANABARRO, Maria Margarete; BASSO, Lourenço Oliveira. Os Professores e as Redes Sociais - É possível utilizar o Facebook par a além do "curtir"?. CINTEDUFRGS, Novas Tecnologias na Educação. V. 11 № 1, julho, 2013.

FERREIRA, Giselle; CAMPOS, Aline; BÁRTHOLO, Helena; MARKENSON, Simone. Facebook e Recursos Educacionais Abertos na Formação de Pesquisadores em Educação: percepções e reflexões, 2014. Educação, Formação \& Tecnologias, 7 (1), 47-60 [Online].

FRAGA, Vinícius; SOUZA, Priscila; TRAJANO, Silvia; MAFFRA, Stella; SOARES, Valéria; NUNES, Wallce; OLIVEIRA, Alexandre. Blog como recurso didático pedagógico no ensino de ciências: as tecnologias de ensino na era dos nativos digitais, 2011. VIII Encontro Nacional de Pesquisa em Educação em Ciências. São Paulo.

FREITAS, Henrique; CUNHA, Marcus; MOSCAROLA, Jean. Aplicação de sistemas de software para auxílio na análise de conteúdo. Rev. de Administração da USP, 32 (3), 97-109, 1997.

GARCIA, Carlos Marcelo. Formação de professores. Para uma mudança educativa. Porto: Porto Editora, 1999.

GARCIA, Carlos Marcelo. Desenvolvimento Profissional: passado e futuro. SísifoRevista das ciências da educação, n. 08, p. 7-22, jan./abr. 2009.

GATTI, Bernardete. A formação inicial de professores para a educação básica: as 
GRANOVETTER, Maicon. Problems of explanation in economic sociology. In: NOHRIA, Nyn; ECCLES, Robert. (Orgs.). Networks and organizations: structure, form, and action. Boston, Mas-sachussetts: Harvard Business School Press, 1992.

HINE, Christine. Virtual Methods and the Sociology of Cyber-Social-Scientific Knowledge. Oxford: Berg, 2005.

IMBERNÓN, Francisco. Formação docente e profissional: formar-se para a mudança e a incerteza. São Paulo: Cortez, 2006

KOZINETS, Robert. Nethnography: doing ethnographic research online. Online Communities. Net, 2010.

LÜDKE, Menga; ANDRÉ, Marli. Pesquisa em educação: abordagens qualitativas. 2. Ed. Rio de Janeiro: EPU, 2013.

MALDANER, Otávio. Desenvolvimento de Currículo e formação de professores de Ciências da Natureza, Matemática e suas Tecnologias. In: FRISON, Marli. (Org.). Cadernos Unijuí: Programa de melhoria e expansão do Ensino Médio - Curso de Capacitação de Professores da Área de Ciências da Natureza, Matemática e suas Tecnologias. ljuí: Ed. Unijuí 2005.

NÓVOA, Antonio. Formação de professores e profissão docente. 3a edição. Lisboa: Publicações Dom Quixote, 1997.

OLIVEIRA, Maria Helena; VASCONCELOS, Teresa. Os portfólios reflexivos na prática pedagógica: implicações da participação do professor cooperante. Da Investigação as Práticas, Lisboa, v. 10, n. 1, 2010.

PIMENTA, Selma; ANASTASIOU, Lea das Graças. Docência no ensino superior. São Paulo: Cortez Editora, 2002.

RECUERO, Raquel. Redes Sociais na Internet. Porto Alegre. Editora Meridional (Coleção Cibercultura), 2009. 191 p.

REZENDE, Flávia. As novas tecnologias na prática pedagógica sob a perspectiva construtivista. Ensaio: Pesquisa em Educação em Ciências. v. 02. № 1. Març, 2002. 
TARDIF, Maurice. Saberes Docentes e Formação Profissional. 8a . edição Petrópolis, RJ: Vozes, 2007.

ZANON, Lenir Basso; SCHNETZLER, Roseli Pacheco. Interações triádicas de licenciandos, professores de escolas e formadores na licenciatura de química/ciências. Enseñanza de las Ciencias, Barcelona: UAB, número especial, Tomo 1, 2001, p. 413-414.

Recebido: 2017-11-13

DOI: $10.3895 /$ rbect.v12n2.7327

Como citar: BEDIN, E.; DEL PINO, J. C. Sentimento docente sobre a prática pedagógica: reflexões e avaliações. Revista Brasileira de Ensino de Ciência e Tecnologia, v. 12, n. 2, 2019. Disponível em: <https://periodicos.utfpr.edu.br/rbect/article/view/7327>. Acesso em: xxx.

Correspondência: Everton Bedin - bedin.everton@gmail.com

Direito autoral: Este artigo está licenciado sob os termos da Licença Creative Commons-Atribuição 4.0 Internacional. 